\title{
Improvement of Polymer Surface Properties Using the Deposition with Thin Metal Alloy Layers
}

\begin{abstract}
ALINA SPANU ${ }^{1}$, DANIEL BESNEA ${ }^{1 *}$, IONELIA VOICULESCU²
${ }^{1}$ University Politehnica of Bucharest, Mechatronics and Precision Engineering Department, 313 Splaiul Independentei, 060042, Bucharest, Romania

${ }^{2}$ University Politehnica of Bucharest, Faculty of Engineering and Management of Technological Systems, Department of Materials Technology and Welding Department, 313 Splaiul Independentei, 060042, Bucharest, Romania

The paper describes the advantages of material deposition using the resistive vaporization method, so that new very thin layer, which is about im, could be used on polymer base structure. Due to the new properties involving the friction coefficient on plane surface, where some dynamic forces are acting, we may better control the performances. By analyzing the theoretical aspects of entropy rate production, we may determine the maximum friction providing the stability of wear avoiding the material deterioration during the process.
\end{abstract}

Keywords: Thin layer, material deposition, friction coefficient, polymer support

New tribological concepts, especially those regarding the modern technology, have improved the theory of friction and wear, have introduced new technological processes in the field of discovering some new material properties. These challenges have been developed and solved in many studies and meantime the results have been applied successfully in the field of micro-mechanical systems, mechatronic products and automotive industry as well.

One of the main new ideas is about the way we may change the physical properties of external surfaces, such as sliding surfaces for instance, meaning the area for applying external forces and the friction could be one of the most important. The friction is acting almost everywhere we have to use mechanical devices with moving parts, producing some negative phenomena starting with the speed and efficiency decreasing as well as accuracy diminution. Moreover, it leads to irreversible processes inside the wear layer of the material it is acting on, so solutions for new material alloy types were found out. Consequently, materials with properties like selforganization, self-lubricating, self-healing and self-cleaning were developed based on properties of some metal alloys.

The required working conditions for these new material alloys are severe and we mention the tensile strength, the elasticity, the value of friction coefficient that has to be constant depending on speed and temperature variation. A solution is to accept a way of making compromise between the imposed properties leading to high performance and the existing technical parameters obtained yet, whether we are using metal alloy of two or more materials.

The demands for new material alloys with higher mechanical and thermal stresses for engine components are the challenges of technologies applied in automotive industry too. In order to improve the wear resistance within the friction contacts of internal combustion engine components various investigations have been made subjected to the most stress and highest working temperature of those parts. Such an example is the top rings of the piston ring package, whose depth-dependent distribution of residual stresses were analyzed in [1]. The analysis was made following the imposed tribological parameters on the hard chrome piston ring coating and its microstructure texture and residual stresses as a function of dissipated frictional energy were studied.
In order to improve the properties of sliding surfaces made of polymers, the Cu-Cr binary alloy could be a solution for material properties demanded for such sliding surfaces due to its tensile strength and its elasticity. The very thin films of such metal alloy could be deposited on polymer substrates, so that wear resistant layers or environmental barrier layers could be used in various technical applications. An unwanted phenomenon could be the film buckling, whose effects are negative from the point of view of mechanical and structural integrity. The studies of buckling strain suggested its increasing by tailoring the film thickness. This mechanism is still studied and the phenomenon is less understood. The authors [2] pointed out the buckling strain of $\mathrm{Cr}$ films increases with the decreasing of its thickness, while for the $\mathrm{Cu}$ films it increases monotonically with the layer thickness. Consequently, even though it is influenced by the delamination process and by the film thickness the way of its behavior is less studied.

The paper concerns with the analyze the authors have made on the very thin $\mathrm{Cu}-\mathrm{Cr}$ layer deposited on the 3D printed polymer surface in order to improve its physical properties when friction force is acting on. The theoretical analysis revealed the dependence of friction coefficient on speed and load acting on the tested surface. The experimental set-up affords the measurements of main parameters characterizing the layer resistance against friction. When the load is greater than a maximum limit, some cracks appeared and their dimensions have been determined.

\section{Theoretical description of the technological process}

The theoretical principle of resistive vaporization is presented in figure 1 . The material is loaded inside a hermetic enclosure (1) and is put on the pot (2) where an electron stream is acting. The bung plate (4) has the role of stopping the deposition whether something wrong happens. Upside there is a vault (5) where the parts we have to cover are placed, so that the unit has a rotational movement around its axis and could be warmed below $300^{\circ} \mathrm{C}$.

Meantime, the layer thickness is controlled by the radiation source (6) with the filter (7) used for the wave length selection. Some other devices for monitoring are the bar for optical monitoring of the thickness (8), the

*email:d_bes@yahoo.com; Phone: 0728907309 


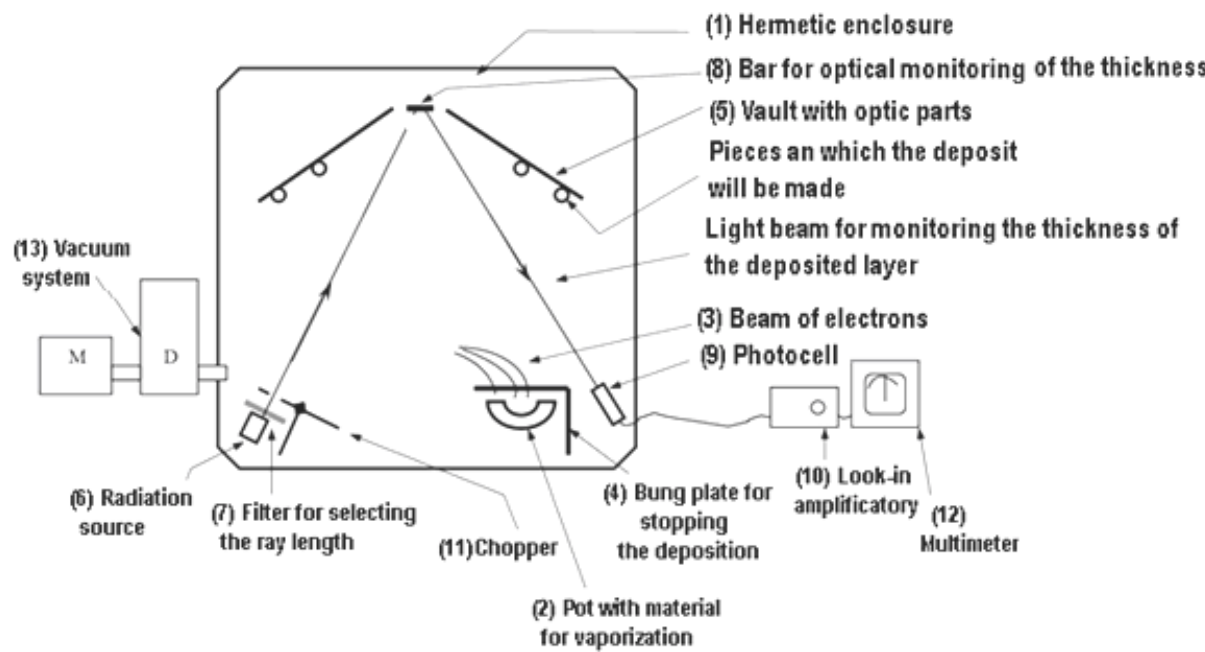

Fig. 1. The schematic of theoretical resistive vaporization concept
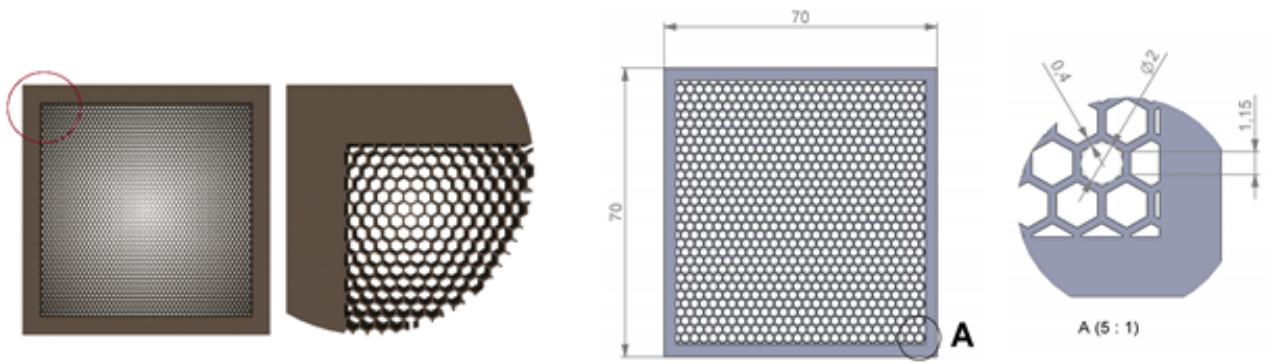

Fig. 2. The final shape of the three-dimensional designed model

photocell (9), look-in amplificatory (10), chopper (11) and multi-meter (12). The vacuum is realized during two working stages: at first is realized the preliminary vacuum with a mechanical pump $M$ and next the higher vacuum value is done with the second pump $D$, which is more precisely.

The working flow starts with material load on the pot, than each part is put in its specific location, under the spherical vault. Since we have positioned the material, the entire room is closed hermetically and the exhaustion starts. Once the preliminary under pressure value is achieved, it starts the warm process of the room until a very well established temperature is achieved, meanwhile the vault is rotated around its axis. When the inside pressure has reached the imposed value, the vaporization starts. If the bung is opened, the exhalations reach the active surface of the parts, the condensation starts, so the deposition takes places.

\section{The technological process for the board manufacturing}

In order to manufacture the hexagonal-board, we have started with the three-dimensional design of the entire shape by using CATIA V5R19 environment. All the dimensions were very accurately designed because of their value range, which was about $250 \mathrm{~mm}$. The final model is presented in figure 2 .

The next stage of our experimental research was focused on three-dimensional printing by using the STL file as it was obtained after we have finished working with the CATIA software and it was loaded in the 3D Pro] et $\circledast 3510$ HD printer.

After we have manufactured the four panels with the 3D printer, there were putinto a room with air-conditioning climate maintenance during an hour, keeping the appropriate temperature 600 needed for removing the native mineral wax used as support for printing. When this process was finished, meaning a percent of $98 \%$ of the wax removed, the immersion in mineral oil was done with all the panels. The leaching vat with mineral oil, whose temperature is 630, had a rotational movement during one hour, so there were cleaned all the surfaces and there were not any more wax particles. Finally, the panels were extracted from the vat and there were lied down on a plane surface for cooling during four hours, then there were washed with ethyl alcohol $90 \%$ proof spirit, so that we may be sure that there is not any particle of wax.

The figure 3 presents the equipment we have used for the technological process of cleaning, that has been done inside an ultrasonic bath during $30 \mathrm{~min}$.

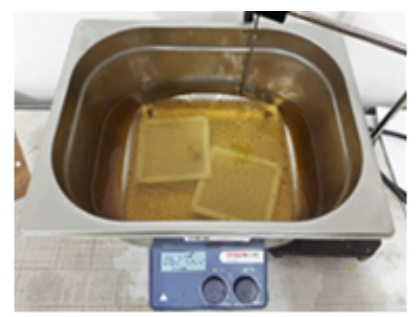

Fig. 3. The main devices we have used for mineral wax removing

Since we have finished the manufacturing and the cleaning process of all four surfaces, we may start the physical vapor deposition based on the coating of very thin layers by heating, vaporization and condensation on the active surface. The entire process is done inside an under pressure room. This very complex plant, named BA 500 Baltzers comprises the next units:

- mechanical pump that has to make vacuum about 10 3 Torr;

- diffusion pump for making vacuum of 10-6 Torr;

- resistive damping based on J oule effect inside Wolfram boat with $0.1 \mathrm{~mm}$ thickness, whose melting point is higher than the melting point of the material we aim to use for deposition. Because the Wolfram boat is heated at 270 only one technological cycle may be allowed, so that it has to be replaced every single time; 300;

- the upside spherical vault that may be warmed under

- the unitnamed GSM 210 has the main task of measuring the laid-down layer thickness.

Figure 4 is a detailed view of the working surface. As this technology comprises, the melting process of the material, which is based on the resistive working principle, 


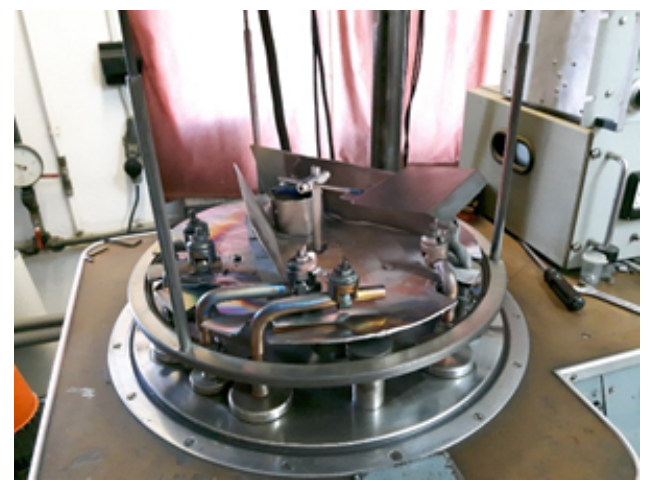

Fig. 4. Detailed view inside the Balzers BA the opened vault

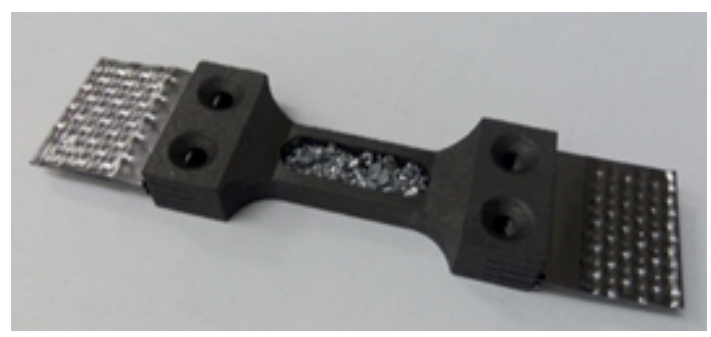

Fig. 5. The boat made of Wolfram

is done inside a boat made of Wolfram, Mo or Ta sheet metal (fig. 5).

\section{The theoretical study of friction influence on the Cu-Crlayer properties}

When the external force such friction is acting on the layer surface, it could lead to energy dissipation and material deterioration, which is known as wear. The most important aspect we have to analyze is the range of friction value applied without any breaking of the layer. The main goal of our study is regarding the behavior of $\mathrm{Cu}-\mathrm{Cr}$ layers when variable friction forces are acting on. The process we aim to study is a non-equilibrium one, because it depends on time and spatial coordinates as well, so the generalized coordinates and forces conducting through an entropy production rate per unit time characterize it. For sliding friction of a body characterized by its position $x$, the flow rate is equal to the sliding velocity $v$ and the thermodynamic force $X$ is the friction force [3]:

$$
X=\frac{\mu \cdot W}{T}
$$

where: $W$-normal load, $T$ - temperature, $\mu$ - friction coefficient.

The rate of entropy production is given by the following equation [3]:

$$
-\frac{\mathrm{d} S}{\mathrm{~d} t}=\frac{\mu \cdot v \cdot W}{T}
$$

When the temperature change has negligible effect on friction, this mathematical equation may be applied. The schematic of the system we have proposed is given in figure 6 , where 1- the electrical stepper motor used for actuation; 2 - the rod with rotational movement generating the friction forces on the layer surface by the intermediate

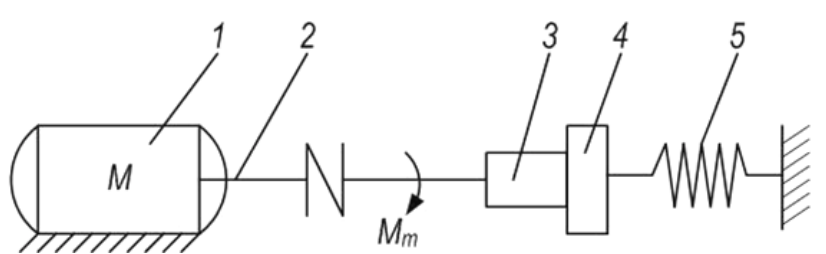

Fig. 6 . The schematic of the proposed system part 3; 4 - the planar surface; 5 - helicoidally spring. The electrical stepper motor with very well-known variable mechanical torque, , generates the rotational movement of the component 3 , which is characterized by an active planar surface. This surface is rotating on the $\mathrm{Cu}-\mathrm{Cr}$ layer and the friction force is acting on. Meantime, the helicoidally spring is acting on the opposite face of same layer having the goal of keeping the surface contact.

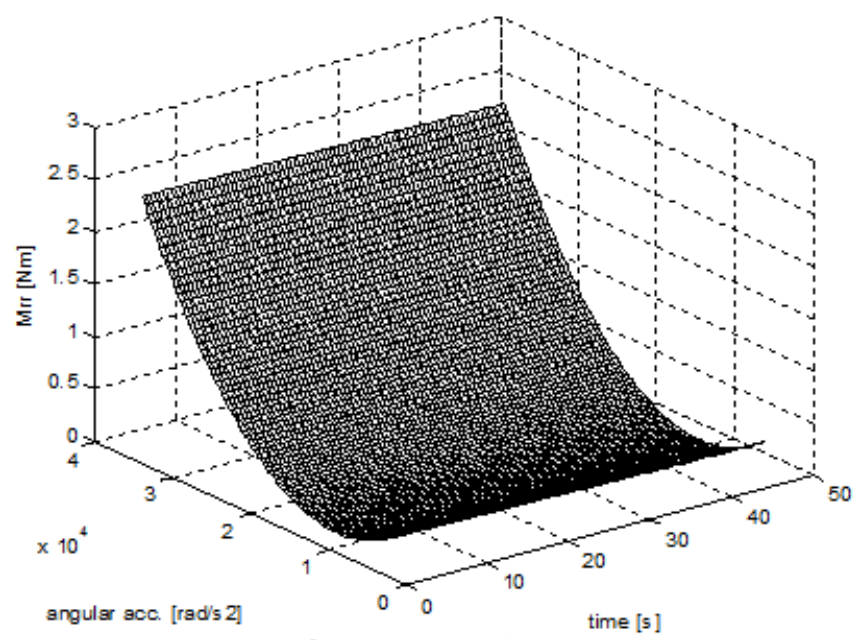

Fig. 7. The variation of friction torque

The friction force generates the variation of the resistant torque, $M_{r r}$ whose dependence on time and angular

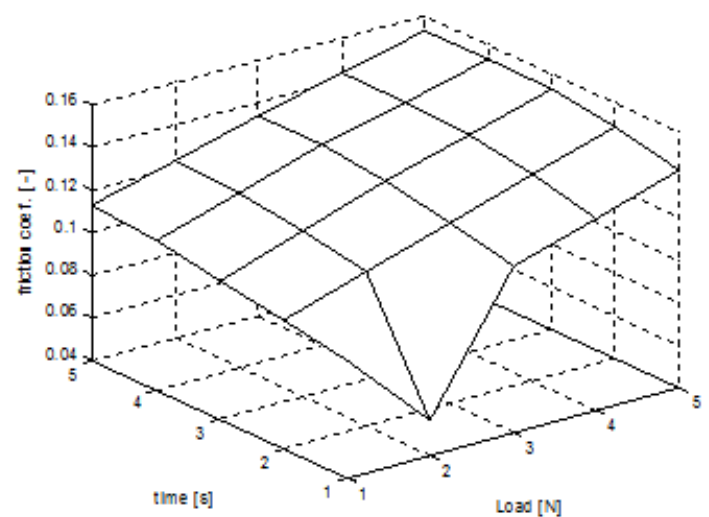

Fig. 8. The variation of friction coefficient as time and load dependence

acceleration is presented in figure 7.

The variation of friction coefficient as time and load dependence is presented in the figure 8 .

Knowing the values for the frictional coefficient of $\mathrm{Cu}$, the first component of the layer, depending on time and normal load [4] we have computed the variation of the entropy production as limit of the process stability with greater or equal zero as condition, considering the following equation [3]:

$$
\frac{1}{2} \cdot \frac{\partial^{2} S}{\partial t^{2}}=\frac{W}{T} \cdot \frac{\partial \mu}{\partial v} \cdot\left(\frac{\partial v}{\partial t}\right)^{2} \geq 0
$$

The second variation of entropy as time dependence (fig. 9 ) is the condition of process stability of the wear.

\section{Experimental part}

As we have described above the schematic of the proposed system, the experimental set-up (fig. 10) comprises the electrical stepper motor 1 , the mechanical clutch 2 and the rod 3 assembled with the profiled component 4 by surface contact constraint. The rotational movement of the part 4 could be very accurately controlled 


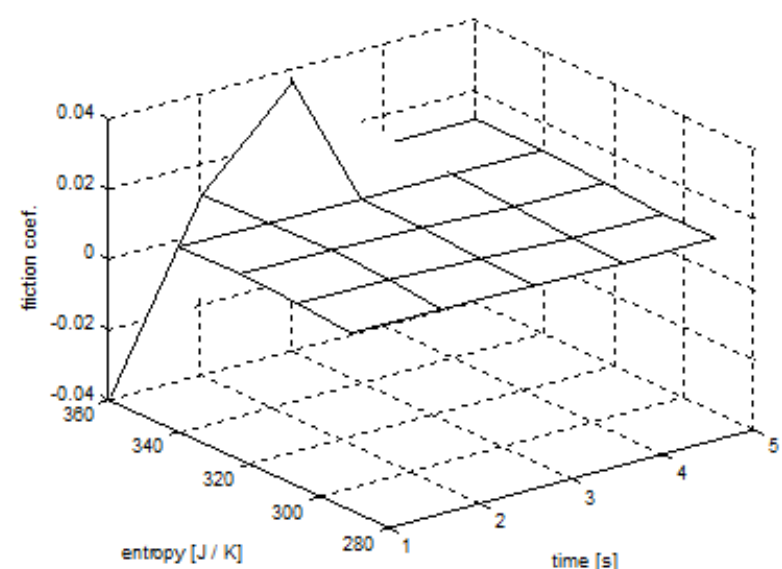

Fig. 9. The friction coefficient as entropy and time dependence

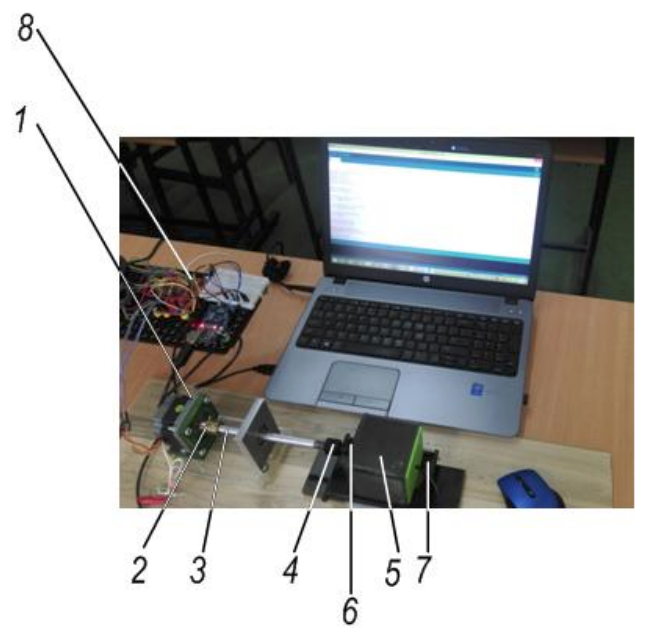

Fig.10. The experimental set-up

as speed dependence on time, so its movement on the tested solid body 5 is well-known. The manufactured tested surface 6 has the outside layer made of $\mathrm{Cu}$, the second layer made of Chrome and the polymer support. The temperature variation was measured with the Texas Instrument transducer 7 during the working period in order to prove its negligible variation during the entire process. The written control software for actuation and temperature control was written for Arduino board 8 . The final measured resultrevealed a variation of about $2^{\circ} \mathrm{C}$ whether we placed the sensor inside the solid body during all the working period, so that we may assume the process entropy variation may be computed following the eq. (2). The accuracy of this sensor is $0.01 \mathrm{deg}$.

The figure 11 is a detailed view of the temperature sensor when it was put outside the solid body.

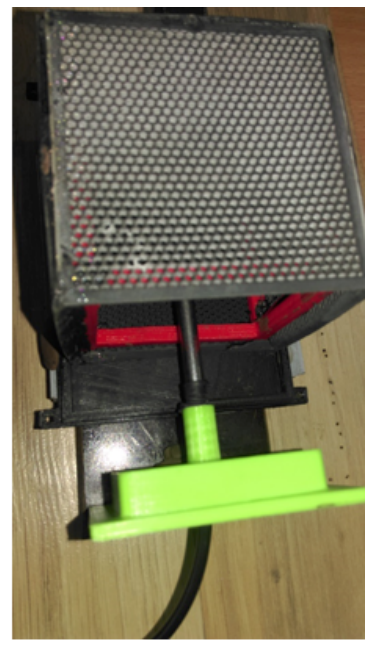

Fig.11. The temperature sensor outside the solid body

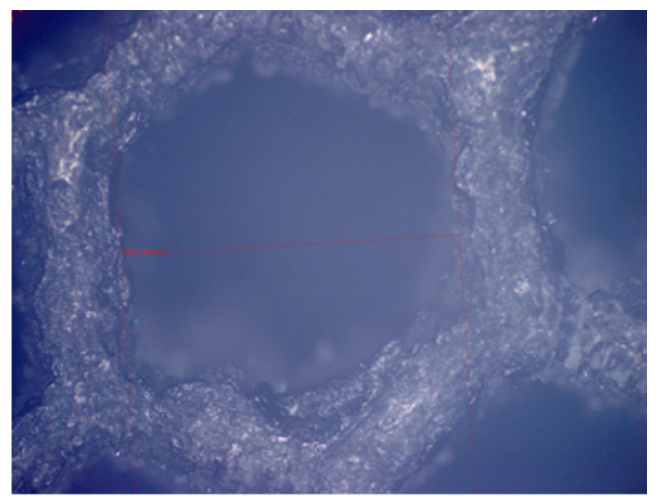

Fig.12. The measured dimension of the hexagonal profile

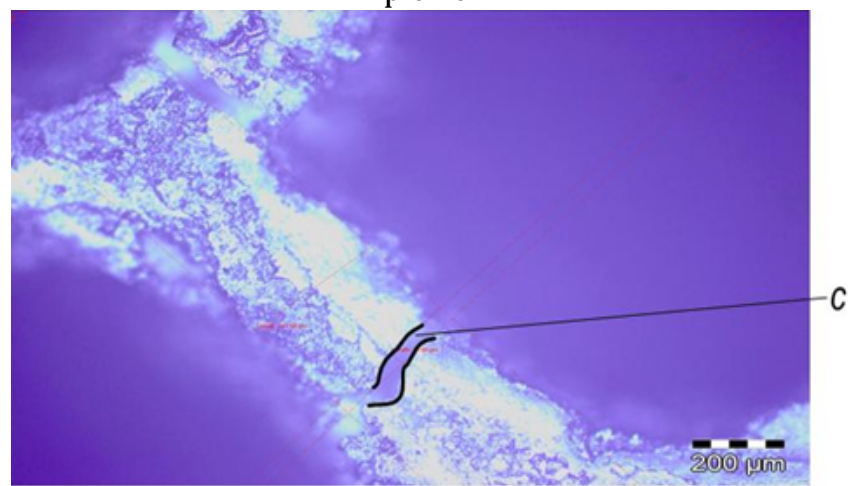

Fig.13. The thickness of the hexagonal network and the crack (c) dimension

\section{Results and discussions}

The microstructure of the sample was influenced by the mechanical stress mainly due to the friction forces. We have analyzed the shape of the surface where the friction has been activated using the Microscope Olympus GX 51 with higher accuracy, which is about $\mu \mathrm{m}$ and the result is presented in figure 12 . The microscope is equipped with digital camera, so high resolution and fast transfers of images are achieved. The software for analyzing the Olympus images affords all the required demanding for analyzing the metallurgical nowadays requirements. At first, we have to mention the dimensions of the hexagonal profile. By using the microscope, we have measured the length of one side of the hexagonal profile of the polymer layer that is $2013.49 \mu \mathrm{m}$, so we have verified the deposition accuracy as well as the resulting shape following a constant pattern resembling in a network.

From figure 13 we may notice the measured thickness of the hexagonal network as it was designed using the three-dimensional modeling and the value is $341.88 \mu \mathrm{m}$. When the friction force reached its maximum value, only one crack has revealed even though the contact area was about $5 \mathrm{~mm}^{2}$. Only one hexagonal profile of the structure has been cracked, so that the very thin layer, which is about im has very good mechanical properties when external forces such friction are acting. The computation of entropy rate production and the analysis of its variation as time and friction dependence have provided all the theoretical information in the estimation of mechanical properties of the analyzed surface. Finally, we may conclude about the maximum values of tensions for these specific polymer surface dimensions we have tested and the use of thin metal alloy layers in order to improve the properties.

\section{Conclusions}

Almost all mechanical assemblies use sliding planes where the friction is a resistant force causing important influences on speed, accuracy and active surface qualities. This is the reason why many studies and challenges point 
out the solutions for minimizing the negative effects and one of them could be the deposition of thin metal alloy layer with improved properties. The paper describes the theoretical aspects regarding the process of friction on such layer taking into account the entropy production rate, so the wear works without damaging. The stability condition has been analyzed theoretically. The second stage of work was the experimental setup testing the plane surface behavior when friction is acting on. The main conclusion was that few cracks appeared when the force exceeds the maximum computed limit.

Acknowledgement: This work has been funded by University Politehnica of Bucharest, through the Excellence Research Grants, Program UPB-GEX 2017. Identify: UPB-GEX2017, Grantno. 48/25.09.2017, ME 14-17-05, ID98.

\section{References}

1. BIBERGER J., FUAER H., J., KLAUS M., GENZEL C., Near-surface and depth-dependent residual stress evolution in a piston ring hard chrome coating induced by sliding wear and friction, Wear 376-377, 2017, p. 1502-1521, available on line www.elsevier.com/locate/wear 2.WU K., YUAN H., Z., LIANG X., Q., ZHANG J ., Y., LIU G., SUN J ., Size dependence of buckling strains of $\mathrm{Cr}$ films, $\mathrm{Cu}$ films and $\mathrm{Cu} / \mathrm{Cr}$ multilayers on compliant substrates, Scripta Materialia, 146, 2018, pp.1-4, available on line www.elsevier.com/locate/scriptamat

3.NOSONOVSKY M., Self-organization at the frictional interface for green tribology, Philosophical Transactions of the Royal Society, 368, 2010, p. 4755-4774

4.CHOWDHURY M.A., NURUZZAMAN D.M., MIA, A.H., RAHAMAN, M.L., Friction Coefficient of Different Material Pairs Under Different Normal Loads and Sliding Velocities, Tribology in Industry, 34, no. 1, 2012, p. 18-23.

5.MANEA, L.,R., DANU, M., C., SANDU, I., Effect of the Applied Electric Voltage and Flow Rate on Electrospun Fibers Diameter, Rev. Chim. (Bucharest), 66, no. 6, 2015, p. 868

6.BRANZEI, M., GHERGHESCU, A., CIUCA, S., Solder Joints Quality Assessments as Function of VPS Process Parameters, Rev. Chim. (Bucharest), 67, no. 6, 2016, p. 1068,

7.COMANEANU, R., M., HANCU, I., D., COMAN, C., HANCU, V., BARBU, H., M., COTRUT, C., M., MITARIU, M., C., MARIS, M., Comparative Study on the Corrosion of $\mathrm{Ni}-\mathrm{Cr}$ and $\mathrm{Co}-\mathrm{Cr}$ Alloys in the Presence of TI6AL4V Implant Abutments, Rev. Chim. (Bucharest), 67, no. 10, 2016, p. 1940

8. IORDACHE, D., M., DUCU, M., C., NITU, E.,L., IACOMI, D., Microstructure and Properties of Copper and Aluminum Alloy Joints by Friction Stir Welding, Rev. Chim. (Bucharest), 68, no. 3, 2017, p. 459

Manuscript received: 25.02 .2018 